\title{
Scientific Review of the Heat-to-Fuel Project ${ }^{+}$
}

\author{
Iván Aranda * and Tatiana Loureiro \\ R2M Solution, Calle Villablanca 85, Despacho 109, 28032 Madrid, Spain \\ * Correspondence: ivan.aranda@r2msolution.com; Tel.: +34-918276597 \\ + Presented at Sustainable Places 2019, Cagliari, Italy, 5-7 June 2019. \\ Published: 19 July 2019
}

\begin{abstract}
Heat-to-Fuel (HtF) is a 48 months Horizon 2020 project which main objective is to deliver the next generation of biofuel production technologies supporting the de-carbonisation of the transportation sector by integrating its novel technologies together with innovative activities on design, modelling, development of hardware and processes, testing and life cycle analysis of a fully integrated system. Reaching almost the half of HtF project, within this short paper a summary review on the main research outcomes and publications will be presented.
\end{abstract}

Keywords: biofuel; decarbonisation; transportation sector; fischer-tropsch; aqueous phase reforming; hydrothermal liquefaction.

\section{Introduction}

Heat-to-Fuel [1] is a Horizon 2020 EU-funded project carried out by 14 partners from across Europe that aims to deliver the next generation of biofuel production technologies supporting the de-carbonisation of the transportation sector.

In numbers, Heat-to-fuel [2] aims to: 1) Deliver cost-competitive technologies achieving biofuel prices below $€ 1$ per litre. This is achieved by a $20 \%$ cost reduction in the biofuel production processes; 2) Increase the quality of the biofuel resulting in 5\% life-cycle green-house gases emissions reduction; 3) Contribute to delivering goals of EU's energy security by increasing the share of local resources used for producing energy, and thus reducing EU's dependency of energy's imports; 4) Support local economies by generating 80-100 direct and 250 indirect jobs each time a new Heat-to-Fuel biorefinery is built; 5) Prove the technological feasibility and economic worthiness of the concept acting as a catalyst of future industrial units.

These overarching objectives will be achieved thanks to the integration of novel technologies in Heat-to-Fuel together with innovative activities on design, modelling, development of hardware and processes, testing and life cycle analysis of a fully integrated system.

At the end of the project, the know-how acquired will allow scalability at a demonstration level before commercialisation, representative of the next generations of sustainable biofuel technologies.

The project, coordinated by the Austrian institution Güssing Energy Technologies, started in September 2017 and will last four years.

\section{About the Project}

\subsection{Why Heat-to-Fuel?}

Transportation fuels corresponded in 2013 to $31.6 \%$ of the final energy consumption in Europe. The source of this energy depends to a large extent on fossil fuels imports. Diesel and kerosene represent, and will remain, two major fuels for heavy trucks and air transportation sectors, respectively. Indeed, the energy density of both fuels, about 35-38 $\mathrm{MJ} / \mathrm{L}$, is unparalleled by other alternative solutions such as batteries, hydrogen, methane and DME. Decarbonised production of 
additive substitutes for fuels and diesel and kerosene (biofuels) as alternative to fossil fuels becomes relevant for reducing carbon emissions of both transport sectors (see Figure 1).

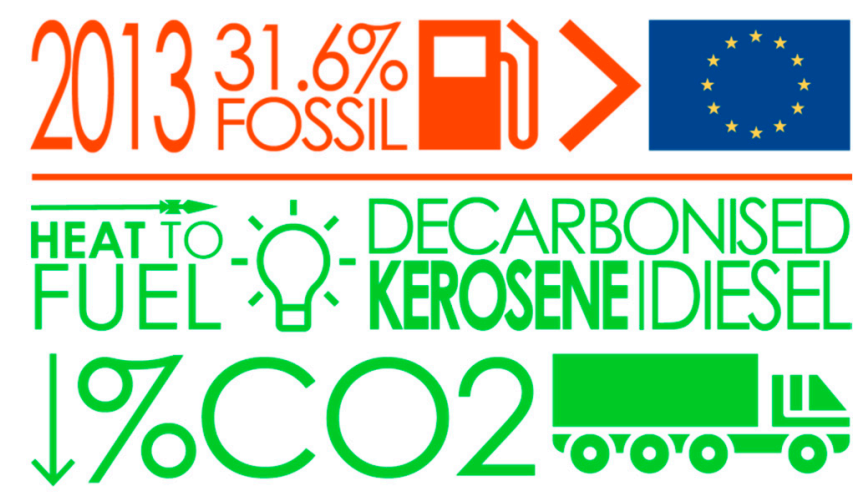

Figure 1. Aim of Heat-to-Fuel (Source: www.heattofuel.eu).

In that perspective, Heat-to-Fuel will investigate and validate an advanced concept integrating dry and wet biomass residues processing, thus exploiting the huge potential of Carbon conversion efficiency improvement arising from this configuration.

Dry biomass and organic waste conversion through gasification routes is characterized by large heat excess, which can be conveniently exploited by wet biomass and waste conversion routes. The combination of those routes is embedded within Heat-to-Fuel spirit, aiming at reaching a carbon conversion efficiency of $50 \%$, and being able to radically improve current targets of organic waste exploitation for biofuels production at the large scale. Thus, Heat-to-Fuel will spearhead EU's research in grasping the opportunity to provide efficient technologies and processes for decarbonised fuels for the transportation sector.

\subsection{Objectives}

In numbers, Heat-to-fuel aims to:

- Deliver cost-competitive technologies achieving biofuel prices below $€ 1$ per litre. This is achieved by a $20 \%$ cost reduction in the biofuel production processes;

- Increase the quality of the biofuel resulting in 5\% life-cycle green-house gases emissions reduction;

- Contribute to delivering goals of EU's energy security by increasing the share of local resources used for producing energy, and thus reducing EU's dependency of energy's imports;

- Support local economies by generating 80-100 direct and 250 indirect jobs each time a new Heat-to-Fuel biorefinery is built;

- Prove the technological feasibility and economic worthiness of the concept acting as a catalyst of future industrial units.

These overarching objectives will be achieved thanks to the integration of novel technologies in Heat-to-Fuel together with innovative activities on design, modelling, development of hardware and processes, testing and life cycle analysis of a fully integrated system (see Figure 2). 

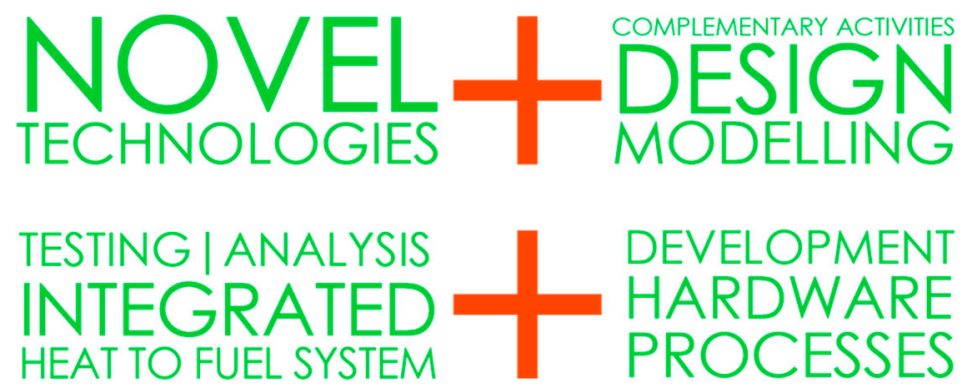

REPRESENTATIVE OF NEXT GENERATIONS OF SUSTAINABLE BIOFUELS TECHNOLOGIES

At the end of the project, the technology will be market ready in around 7 years The know-how acquired will allow scalability at a demonstration level before commercialisation

Figure 2. Heat-to-Fuel results (Source: www.heattofuel.eu).

\subsection{Consortium}

The consortium comprises 14 entities from 7 EU countries: 6 industrial partners $(2$ technical SMEs, 2 technology transfer and risk analysis SMEs, and 2 large component manufacturing industries); one end user from the transportation sector; 5 RTD and 2 HEA organizations to research and develop cutting-edge technologies. The consortium combines skills and expertise, bringing to the project a wide range of experts working with transdisciplinary approaches to environmental and industrial processes challenges.

\section{Scientific Review}

Reaching the equator of the project several scientific publications have been released confirming the applicability of the proposed HtF concept. Those research activities will set the groundwork to demonstrate the approach as well as to overpass the current state-of-art in the field. Among the main results achieved so far, it is worthwhile mentioning the following key publications:

\subsection{Towards the Sustainable Hydrogen Production by Catalytic Conversion of C-Laden Biorefinery Aqueous} Streams [3]

Abstract and conclusions: An extensive screening of representative molecules of a post-hydrothermal process side stream has been performed with the aim of producing a gas mixture rich in hydrogen by catalytic aqueous phase reforming. The survey enlightens possible routes of valorisation of these by-products, scarcely investigated with other processes so far. The influence of reaction temperature was studied in the $230-270{ }^{\circ} \mathrm{C}$ range, looking at both the composition of the gas phase and the characterization of the liquid products. Binary and ternary mixtures of four selected compounds were tested to investigate synergistic and inhibiting effects, going towards the direction of a real biorefinery stream. The spent alumina-supported catalyst was characterized, outlining possible deactivation mechanisms of the catalytic system, and reused in two successive tests. Thanks to this work, HtF project is contributing to fill a gap in the field of the hydrothermal processes, where there is a lack of information in the study of the C-laden aqueous phases and their valorization.

\subsection{Lignocellulosic Ethanol Biorefinery: Valorization of Lignin-Rich Stream through Hydrothermal Liquefaction [4]}

Abstract and conclusions: Hydrothermal liquefaction (HL) of lignin-rich stream from lignocellulosic ethanol production at an industrial scale was carried out in a custom-made batch test bench. Light and heavy fractions of the HTL biocrude were collected following an ad-hoc developed two-steps solvent extraction method. A full factorial design of experiment was performed, investigating the influence of temperature, time and biomass-to-water mass ratio $(\mathrm{B} / \mathrm{W})$ on product yields, biocrude elemental composition, molecular weight and carbon balance. Total biocrude yields ranged from $39.8 \%$ to $65.7 \% \mathrm{w} / \mathrm{w}$. The Temperature was the main influencing parameter as regards the distribution between the light and heavy fractions of the produced biocrude: the highest amount 
of heavy biocrude was recovered at $300{ }^{\circ} \mathrm{C}$, while at 350 and $370{ }^{\circ} \mathrm{C}$ the yield of the light fraction increased, reaching $41.7 \% \mathrm{w} / \mathrm{w}$ at $370{ }^{\circ} \mathrm{C}$. Instead, the $\mathrm{B} / \mathrm{W}$ ratio did not have a significant effect on light and heavy biocrude yields. As proposed in HtF project, this research points out the suitability of HL for the valorization of lignin-rich streams coming from the bioethanol industry.

\section{3. $\mathrm{CO}_{2}$ Gasification in a Dual Fluidized bed Reactor System: Impact on the Product Gas Composition [5]}

Abstract and conclusions: The use of $\mathrm{CO}_{2}$ as gasification agent in the $100 \mathrm{kWth}$ dual fluidized bed gasification pilot plant was investigated at TU Wien. For this purpose, steam as gasification agent was replaced stepwise by $\mathrm{CO}_{2}$. Softwood was used as fuel and olivine as bed material. Starting from 100 vol.- $\%$ steam as gasification agent, substituting it by 32, 45 and finally 68 vol.- $\% \mathrm{CO}_{2}$. Additionally, a $\mathrm{CO}_{2}$ gasification test campaign was investigated. For this case, the gasification agent was composed of 65 vol.- $\% \mathrm{CO}_{2}$ and 35 vol.- $\%$ steam. The use of $\mathrm{CO}_{2}$ as gasification agent led to changes of the product gas. Instead of a $\mathrm{H} 2$-enriched product gas, which was produced during steam gasification, $\mathrm{CO}$ and $\mathrm{CO}_{2}$ occupied the major share of the product gas. Consequently, the $\mathrm{H} 2 / \mathrm{CO}$ ratios as well as the lower heating values decreased when substituting steam by $\mathrm{CO}_{2}$. Tar contents were lower for $\mathrm{CO}_{2} /$ steam gasification compared to pure steam gasification. In the frame of the $\mathrm{HtF}$ project, encouraging results have been found regarding recycling $\mathrm{CO}_{2}$ for biomass gasification. This approach presents a promising concept to produce biofuels in the future, however, further research is required in order to enhance the $\mathrm{CO}_{2}$ conversion.

\section{Conclusions}

The Heat to Fuel project is been very active carrying out an intense research activity. This research effort is not only validating the $\mathrm{HtF}$ concept, but also surpassing the current state of the art, while pointing out the pathway to successfully produce a new generation of biofuels. The researching activities are ongoing and new publications are about to be released.

Funding: This research was funded by the European Union's Horizon 2020 research and innovation programme under Grant Agreement number 764675.

Conflicts of Interest: Conflict of Interest: The authors declare no conflicts of interest.

\section{References}

1. Heat-to-Fuel Page in CORDIS. Available online: https://cordis.europa.eu/project/rcn/211646_en.html (accessed on 26 June 2019).

2. Heat-to-Fuel Website. Available online: http://www.heattofuel.eu/ (accessed on 26 June 2019).

3. Pipitone, G.; Zoppi, G.; Ansaloni, S.; Bocchini, S.; Deorsola, F.; Pirone, R.; Bensaid, S. Towards the sustainable hydrogen production by catalytic conversion of C-laden biorefinery aqueous streams. Chem. Eng. J. Available online: https://zenodo.org/record/2638021\#.XRSBw-gzbIU (accessed on 18 July 2019).

4. Miliotti, E.; Dell'Orco, S.; Lotti, G.; Rizzo, A.M.; Rosi, L.; Chiaramonti, D. Lignocellulosic Ethanol Biorefinery: Valorization of Lignin-Rich Stream through Hydrothermal Liquefaction. Energies 2019, 12, 723.

5. Mauerhofer, A.; Fuchs, J.; Müller, S.; Benedikt, F.; Schmid, J.C.; Hofbauer, $\mathrm{H}_{\text {. }} \mathrm{CO}_{2}$ gasification in a dual fluidized bed reactor system: Impact on the product gas composition. Fuel Available online: https://zenodo.org/record/3233549\#.XRSHlugzbIU (accessed on 18 July 2019).

(c) 2019 by the authors. Licensee MDPI, Basel, Switzerland. This article is an open access article distributed under the terms and conditions of the Creative Commons Attribution (CC BY) license (http://creativecommons.org/licenses/by/4.0/). 